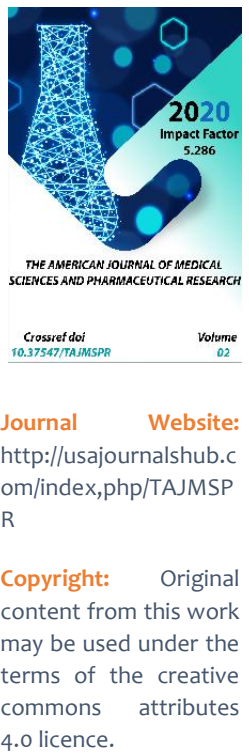

\section{Features Of The Anamnesis Of Women With The Threat Of Miscarriage And Their Role In Determining The Risk Group}

Solieva N.K.

Bukhara State Medical Institute Named After Abu Ali Ibn Sino, Bukhara, Uzbekistan

Negmatullaeva M.N

Bukhara State Medical Institute Named After Abu Ali Ibn Sino, Bukhara, Uzbekistan

Sultonova N.A

Bukhara State Medical Institute Named After Abu Ali Ibn Sino, Bukhara, Uzbekistan

\title{
ABSTRACT
}

Determine the role of studying socio-biological factors and obstetric-gynecological history in predicting and early diagnosis of the threat of termination in the first trimester of pregnancy. We analyzed 210 case histories of patients who were treated in the gynecological department of the Perinatal Center in Bukhara and were observed in antenatal clinics No. 6 and No. 11 of the same city for the period of 2019. All pregnant women were divided into two groups. The main I-group consisted of 110 women, whose pregnancies with the threat of termination with clinical symptoms pain in the lower abdomen with the onset of the 1st trimester at gestation periods from 5 to 12 weeks. The control group included 100 patients with the physiological course of pregnancy II group.

\section{KEYWORDS}

Miscarriages, pregnancy, threat.

\section{INTRODUCTION}

Miscarriage is a common pathology According to $\mathrm{WHO}$, despite the progress throughout the world during gestation. achieved in the obstetric and gynecological 
service, the frequency of miscarriage remains stable and reaches $25 \%$ of the number of births; recurrent miscarriage accounts for $5-7 \%$ of all pregnancies. It is extremely important to remember that repeated miscarriages can reduce the chance of successfully carrying the next pregnancy, but even after numerous losses, this chance remains.

The likelihood of a favorable prognosis, depending on the cause, is almost always higher than the risk of recurrence. The reasons for any loss of pregnancies, including repeated ones, are random (spontaneous) and non-random (regular). This sorting is important for assessing the risk of recurrence, but not always possible. The frequency of miscarriage is influenced by many different factors. On this issue, scientific studies were carried out that demonstrated the polyetiological nature of miscarriage: from socio-biological factors and anamnestic data to the characteristics of the course of pregnancy at different stages.

This pathology has a polygamous etiology, and therefore, the study of social - anamnestic data is of great importance in determining and establishing a risk group. In modern obstetrics, many causes of miscarriage remain far from being resolved.

\section{PUPROSE OF STADY}

Determine the role of studying sociobiological factors and obstetric-gynecological history in predicting and early diagnosis of the threat of termination in the first trimester of pregnancy.

\section{MATHERIALS AND RESEARCH METHODS}

We analyzed 210 case histories of patients who were treated in the gynecological department of the Perinatal Center in Bukhara and were observed in antenatal clinics No. 6 and No. 11 of the same city for the period of 2019. All pregnant women were divided into two groups. The main I-group consisted of 110 women, whose pregnancies with the threat of termination with clinical symptoms - pain in the lower abdomen with the onset of the 1st trimester at gestation periods from 5 to 12 weeks. The control group included 100 patients with the physiological course of pregnancy II - group.

In the age aspect, the average age of patients with clinical manifestations of the threat of termination of pregnancy was significantly higher compared to women with the physiological course of pregnancy, amounting to $24.5+-0.5$ versus $21.6+-0.4$ LER $(p<0.05)$. Both groups of patients were identical in terms of height - weight ratio, age of sexual debut, age at menarche, use of COCs.

At the same time, women with the threat of termination of pregnancy were significantly more lonely $(18.5 \%+-2.3 \%)$ and were significantly less likely to be in a civil marriage $(25+-6 \%$ versus $6.5+-3 \% p<0.001) \ldots$ Women in group -1 had a greater number of pregnancies $(2.48+-0.2$ versus $1.75+-0.2, p$ $<0.05)$. The patients of the study group had a history of spontaneous miscarriages by 10 times more than in the control group.

\section{CONCLUSION}

In the general analysis of blood in women of group 1, a significantly greater number of erythrocytes $3.84+-0.05$ versus $3.12+-0.06 p$ 
$<0.05)$ and leukocytes ( $8.0+-0.20$ versus 6,12 $+-0.18 p<0.05)$. In the general analysis of urine in women of the main group, 3 times more leukocytes were found, but these indicators, nevertheless, do not go beyond the generally accepted norms. Women with a threat of miscarriage were less likely to use barrier contraception, 50\% less than the physiological course of pregnancy.

Thus, all of the above factors and signs will manifest themselves in a pregnant woman, then she can be attributed to the risk group for the development of the threat of miscarriage, which makes it possible to predict this pathology and diagnose its early stages and take timely preventive measures to improve.

\section{REFERENCES}

1. Babadjanova G.S. // Determination of the effectiveness of treatment of recurrent miscarriage caused by some types of TORCH infections. Problems of pregnancy.-2018.-№2.-p.61-64.

2. Borisova A.B. // Optimization of management tactics for women with recurrent miscarriage and chronic viral infection, taking into account interferon status. Diss. Ph.D., - M. - 2017.

3. 3. Demidov V.N., Stygar A.M. // The value of echography in the diagnosis and identification of the causes of miscarriage. Miscarriage, -M., 2016.-P.91-92.

4. DI Tuksonova, NK Solieva, MN Negmatullaeva, TI Shamsieva. // The value of the immune status in miscarriage. News of dermatovenerology and reproductive health. 2020.-№1.-st 52 -54.

5. Ledina A.B.// Management of women with recurrent miscarriage against the background of persistent enterovirus infection. Dis. c. m. n. Moscow. - 2016. 140.
6. Solieva N.K., Tuksonova D.I. Tibbiyotda yangi kun .2020.-2 (30-2) .st 294-297.

7. Malysheva P.A., Tishkina V.A. // Prognostic value of signs of threatened abortion for pregnancy and childbirth outcomes. Akush. and gynecological .- 2018.- No. 2.p.58-60.

8. Schelykalina L.A. // Study of interferon in women with physiological pregnancy and the threat of termination of pregnancy. Abstract of the thesis. Dis. Ph.D., Novosibirsk, 2015.

9. Sherman R. P., Garrett W.J. // Double-Blind Study of Effect of 17Hydroxyprogesterone Caproate on Abortion Rate. Brit. Med. J., 2013, v.292, №I,p. 5326-5329.

10. Wheeler D.M., Sinosich M J.,(2018). // Prenatal screening in the first trimester of pregnancy, Prenat. Diagn., 18, 6, 537-544.

11. Yamada H., Polgar K., Hill J.A.// Cellmediated immunity to trophoblast antigens in women with recurrent spontaneous abortion. Am. J. Obstet. Gynecol.- 2014.-May. 170(5Pt 1). -p. 13391344. 